Article

\title{
Journey Making: Applying PSE Principles to Complex Curriculum Designs
}

\author{
Ian Cameron * and Greg Birkett
}

School of Chemical Engineering, The University of Queensland, Brisbane 4072, Australia; g.birkett@uq.edu.au

* Correspondence: itc@uq.edu.au

Received: 7 November 2019; Accepted: 16 March 2020; Published: 23 March 2020

\begin{abstract}
Since the 1950s, Process Systems Engineering (PSE) concepts have traditionally been applied to the process industries, with great effect and with significant benefit. However, the same general approaches and principles in designing complex process designs can be applied to the design of higher education (HE) curricula. Curricula represent intended learning journeys, these being similar to the design of process flowsheets. In this paper, we set out the formal framework and concepts that underlie the challenges in design of curricula. The approaches use generic and fundamental concepts that can be applied by any discipline to curriculum design. We show how integration of discipline-specific concepts, across time and space, can be combined through design choices, to create learning journeys for students. These concepts are captured within a web-based design tool that permits wide choices for designers to build innovative curricula. The importance of visualization of curricula is discussed and illustrated, using a range of tools that permit insight into the nature of the designs. The framework and tool presented in this paper have been widely used across many disciplines, such as science, engineering, nursing, philosophy and pharmacy. As a special issue in memory of Professor Roger W.H. Sargent; we show these new developments in curriculum design are similar to the development of process flowsheets. Professor Sargent was not only an eminent research leader and pioneer, but an influential educator who gave rise to a new area in Chemical Engineering, influencing its many directions for more than 50 years.
\end{abstract}

Keywords: process systems engineering; design; higher education; curricula; visualization

\section{Introduction}

Curriculum design stands at the heart of all education. It is a multiscale challenge across different time and space scales-from whole-of-curriculum design considerations, to distinct learning units or modules, down to the day-to-day learning elements at the lowest level of consideration. It spans sequential stages of learning-from early learners, primary, secondary, tertiary and continuing professional development (CPD). By necessity, curriculum designs seek to embody stated intended outcomes for learners that address knowledge domains, application of knowledge, and personal- and professional-attribute development.

It might seem strange to some that curriculum design could be intimately related to Process Systems Engineering (PSE) thinking and application. In what follows, we show the development of complex curricula from the basic underlying concepts and building blocks that mirror many aspects of PSE. In doing so, we emphasize that PSE possesses a much broader interpretation and application than has traditionally been adopted.

In 1967, Roger Sargent wrote in Chemical Engineering Progress a review on "Integrated Design and Optimization of Processes". He stated the following: "Although we are in sight of a truly integrated approach to design of complete processes, a great deal of work remains to be done. With the need for more sophisticated analysis of larger complexes, it is more important than ever to join hands with those 
working in the fields of control engineering, operational research, numerical analysis and computer science" [1].

The discipline area of PSE arose from the application of systems engineering concepts to industrial processes [2,3]. The 1960s was a period of rapid digitalization in industry, affording significant advances in modeling, control, optimization and new computer-based numerical methods. The focus on "engineering" of "systems" that were primarily within the "process" industries drove PSE as a new focus within Chemical Engineering. The concept of "engineering" as ingenuity in design, using thinking and practices around a set of things that work together ('system'), can be applied to the general idea of any "process". That liberates PSE from the narrow confines of industrial and manufacturing sectors.

The 1967 statements of Roger Sargent, adapted to the case of curricular design, ring true. The tasks require an integrated approach that ensures the final curriculum design is "fit-for-purpose". It is a complex set of tasks dealing with many interconnected learning units, their attributes and intended outcomes. The appropriate sequencing of learning, as well as generating deep insights into the nature and behavior of the design, is essential. It is also a task where the skills and insights of numerous people are necessary to arrive at designs that deliver the requisite outcomes. In short, it bears many resemblances to traditional PSE thinking and practices.

Curriculum design practice has a long and important history. The rapid expansion of human knowledge in all professional domains has increased the need for learning designs that must meet the demand of current and future work demands in ever-changing environments. That is a long-standing challenge, and one that continues to challenge educators.

Early work by Dewey [4] and others, such as Tyler [5], set the scene for modern curriculum considerations. The expanding digitalization trends across society, with the creation and growth of the internet, have brought the need to use enabling information technologies, visualizations and user-centered web systems, to improve curriculum designs and their deployment. These information and communication technologies (ICT) can enhance the curriculum design process. The design process relies on structured information and its use to create educational pathways for learners.

In what follows, we outline why curriculum design and deployment is important, the basic concepts and processes that help engineer the learning system and our ability to assess designs in both qualitative and quantitative ways. Section 2 deals with design purpose and practice, before turning in Section 3 to the fundamental concepts and building blocks that permit designers to assemble a range of desired learning pathways. Section 4 shows the principles in practice, using an actual case study in Chemical Engineering at The University of Queensland. The final section considers how many other disciplines have derived benefit from a systems design environment that was pioneered within Chemical Engineering.

\section{Curriculum Design: Purpose and Practice}

\subsection{Purpose}

Curriculum designs set out the key learning pathways that an educational organization places before a learner. That is, curricula represent learning journeys, hence the title of this paper: "Journey Making".

"Curriculum" is related to the Latin word "currere", meaning "to run". As such, it speaks of a pathway or a course traversed by participants to reach a goal. End-goals and intermediate goals are crucial outcomes within curricula. The attainment of such goals is incremental.

In the last few decades, the underlying principles of curricula have been revisited and emphasized by prominent educational researchers across many disciplines [6,7]. These researchers and practitioners have enhanced earlier understandings of the role of curricula, the educational psychology around learning and the science of learning $[8,9]$. 
Barnett and Coate [6] recognized "that curricula have distinctive, but integrative components, as well as allowing for different weightings of each domain within any one curriculum" (p. 70).

It is not just academic researchers who are interested in curriculum design and outcomes. Due to the professional nature of engineering registration, practice and graduate mobility, global organizations such as the International Engineering Alliance (IEA), as represented by the Washington Accord [10], "establish and enforce internationally bench-marked standards for engineering education and expected competence for engineering practice".

In the case of the IEA, 29 countries that span the globe are signatories to that agreement. The professional engineering bodies or accreditation agencies in each country administer the accreditation of programs and curricula for higher education institutions that produce graduate engineers. In the USA, the Accreditation Board of Education \& Technology (ABET, Baltimore, MD, USA) administers undergraduate degree programs [11]. Other organizations such as the European Network for Accreditation of Engineering Education (ENAEE), administer the EUR-ACE accreditation system for engineering graduates [12].

This means that, for accreditation of engineering programs across most of the globe, there are necessary learning outcomes that must be seen within the curriculum design, and importantly the evidence gathered to show that graduate engineers display those outcomes to an acceptable level. As well as the professional incentives for curriculum design, there are important institutional incentives in terms of developing curricula that sets apart one institution from another. This is often seen in terms of the learning pathways that students travel through during their undergraduate and graduate programs.

This raises the importance of excellence in curricular design and delivery. PSE-type approaches can provide the rigor necessary to achieve innovative, accredited curricula that provide flexibility in learning pathways to reach intended outcomes. PSE principles related to output requirements, integrated system and quality control through measurement and assessment strategies naturally fit into curriculum considerations.

\subsection{Practice}

Curriculum design practice across the higher education (HE) sector is extremely varied in the processes adopted to imagine what needs to be done, as well as the tools that might aid in developing, understanding and displaying designs. Many institutions struggle to properly design and document outcomes. Many designs are done by a small group of discipline experts with little 'buy-in' from colleagues. Many academics are not aware of the design principles and how their specific learning units integrate into the whole curriculum.

In recent years, a number of tools have been developed to help disciplines address the design activities in a structured manner. These primarily are mapping tools for learning outcomes (LOs), and they are limited in scope for doing comprehensive curriculum design across all higher education disciplines [13-15]. Some systems such as SOFIA have more pathway features [16]. Early comprehensive work in this space was done by the authors within Chemical Engineering [17]. PSE approaches can help in organizing curriculum around key elements that are combined to address intended learning outcomes and tracking those outcomes through the curriculum. This can help with the design process.

\section{Curriculum Design: Underlying Concepts, Building Blocks and Pathways}

In this section, we investigate the fundamental concepts upon which curriculum design rests. We consider the following questions:

1. What are the overarching outcomes that underlie curricular designs?

2. What are the fundamental building blocks that help generate learning designs?

3. What are the vital pathways that are to be considered and embedded as part of the design? 


\subsection{Basic Concepts}

What are we trying to achieve in curriculum design? This is a crucial question to consider before undertaking any design activities. It mirrors the focus of Requirements Engineering in seeking to define a functional specification of the needs and desires of stakeholders [18]. The general equivalent in curriculum is the Intended Learning Outcomes (ILOs). A survey of the key literature, including national and international accrediting agencies and research monographs, shows that educational program requirements are in three major areas [11,19-21]. Figure 1 displays the schema of Barnett and Coate [6] that covers these requirements.

1. Knowing: this is the engagement of learning with knowledge;

2. Acting: this is the performative character in learning, namely putting knowledge to work in various circumstances and changing contexts;

3. Being: this is the personal and professional development of the learner. It addresses self-relationships, the educational setting and the outside world.

There is an intentional overlap in this schema, emphasising that all three elements combine synergistically toward the development of graduate capabilities. This schema is not confined to engineering disciplines, but has universal application.

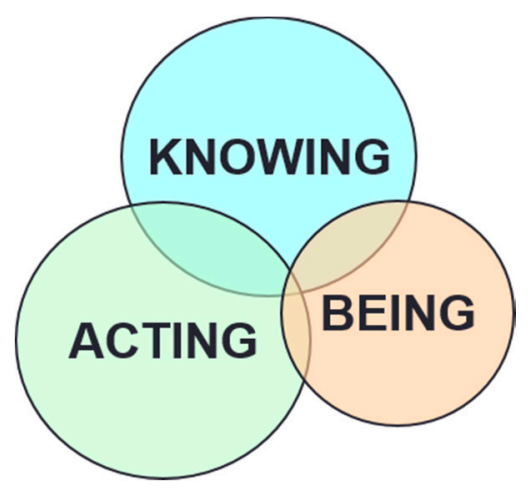

Figure 1. Educational schema as the major focus of educational designs.

Figure 2 shows the engineering program outcomes schema for Engineers Australia, the peak professional body in Australia. The accreditation frameworks in the USA and Europe, including The Washington Accord signatories, have a similar schema.

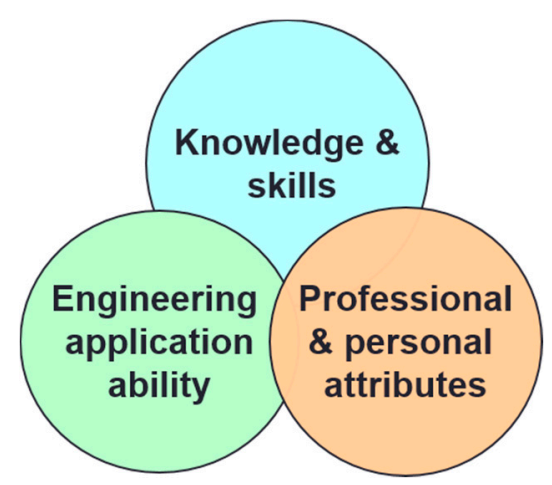

Figure 2. Engineers Australia, Stage 1 competency schema.

From this high-level schema, it is clearly necessary to develop more detailed outcomes at the level of the individual learning-unit level and show how integration across learning units addresses the outcomes within the Knowing, Acting and Being schema. 


\subsection{Building Blocks}

Similar to flowsheet development that deals with processing units and the connected streams, curriculum development requires description of the learning units or modules. In some institutions, these are called "courses" or "subjects". They represent the lowest-level learning and teaching element in a degree program. The connections between units show required prior learnings (RPL). Besides these topological elements, the development of Intended Learning Outcomes (ILOs) for individual learning units, and subsequently the whole curriculum, require a wide range of other important elements. Figure 3 shows the key elements related to the process leading to the "curriculum as designed" stage.

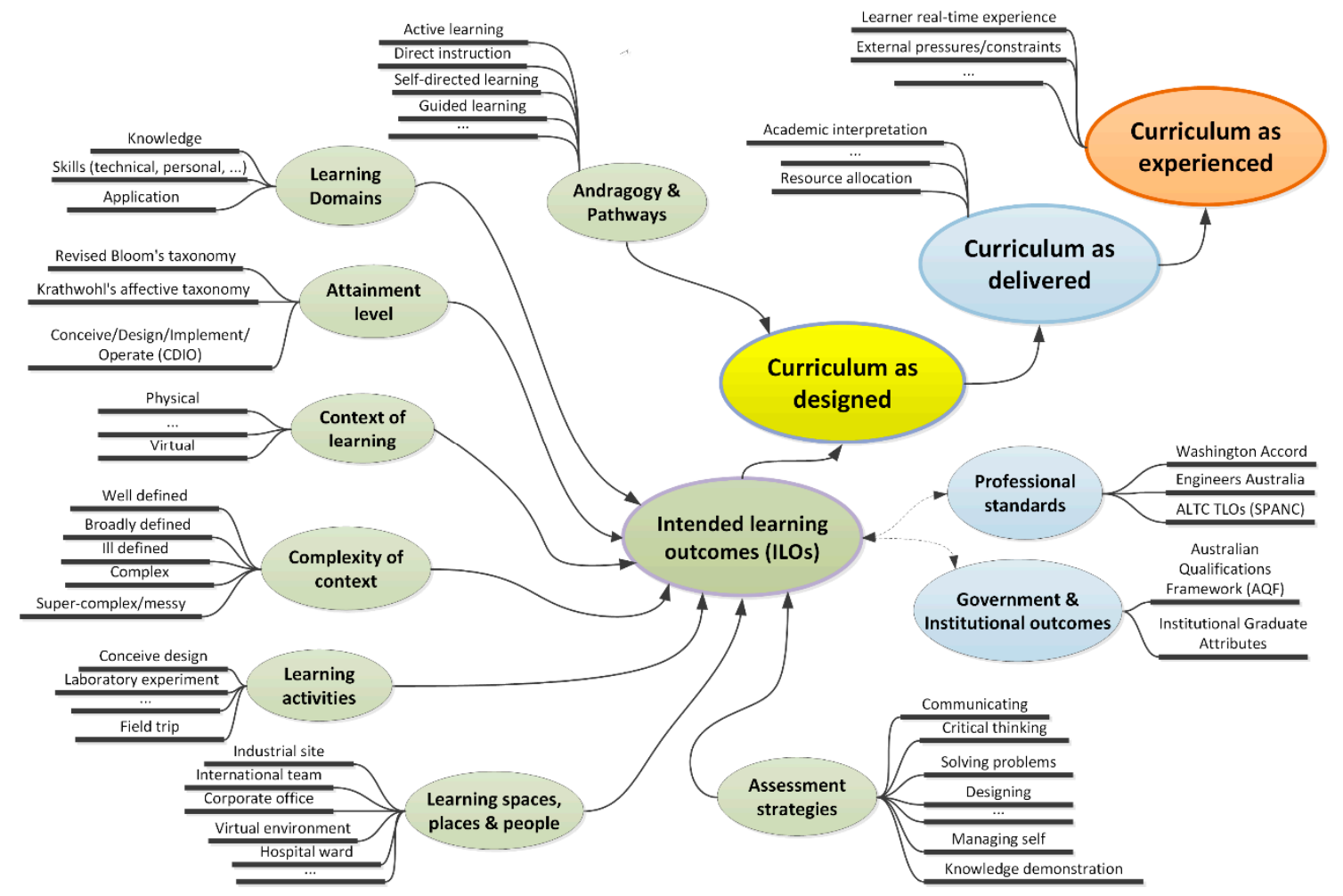

Figure 3. Curriculum design building blocks and information.

It should be noted that, beyond "curriculum as designed", there are two further concepts: "curriculum as delivered" and "curriculum as experienced". These concepts relate to the actual delivery of the curriculum by instructors and staff to student engineers, and the curriculum as actually experienced by the students. These are important concepts, but discussion of these is beyond the focus of this paper.

It should be noted that, in many higher education institutions, students have the ability to design their own personalized curriculum. Currently, for many students, it is difficult for them to see the connections between learning unit choices, sometimes leading to fragmentation in the overall curriculum. Moreover, over time, well-designed curricula can fragment, as learning units change with little consideration given to the implication of those changes on other integrated learning units.

\subsubsection{Information Management}

In order to gain maximum benefit from the development of a computer-aided environment for curriculum design, it is important that the information contained in these elements is both organized and extensible within data structures. We can classify the elements into two main categories:

1. Generic concepts;

2. Specific concepts. 
Generic concepts are not discipline-specific, but need to be extensible and editable. They could include learning activities, attainment levels or assessment strategies. They are vital in developing the learning-outcome statements. Specific concepts relate to the discipline area considered in the design. Obvious specific areas would be discipline knowledge and application.

Taxonomies can be used to capture and utilize the important terms within an area. For example, the concept of "attainment level" can be organized as a multilevel taxonomy that is fully editable and extensible with the ability to select synonyms as needed. Figure 4 shows part of an attainment taxonomy within a design environment. It shows three key taxonomies often used in building learning outcomes.

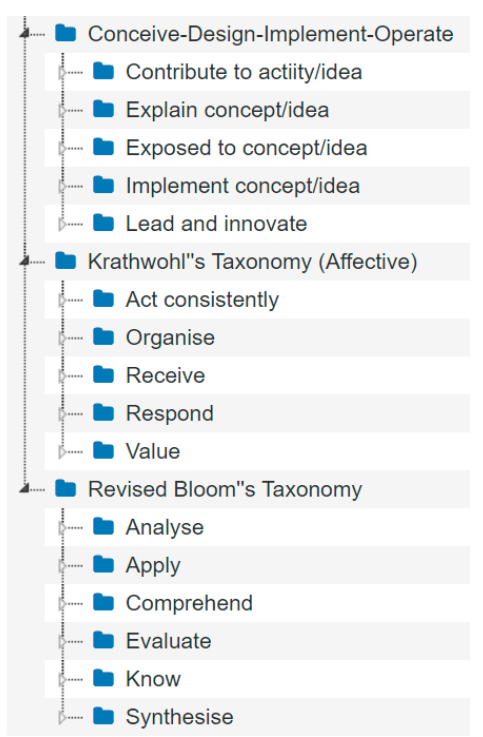

Figure 4. Part of an "attainment" taxonomy for building ILOs.

Similar approaches can lead to taxonomies for all the elements within Figure 3. Of particular interest are the discipline-specific knowledge taxonomies. Figure 5 shows a taxonomy for Chemical Engineering that is both extensible and editable within the design environment. It consists of levels that express a domain, sub-domain and topic taxonomy. This is clearly a multilevel view.

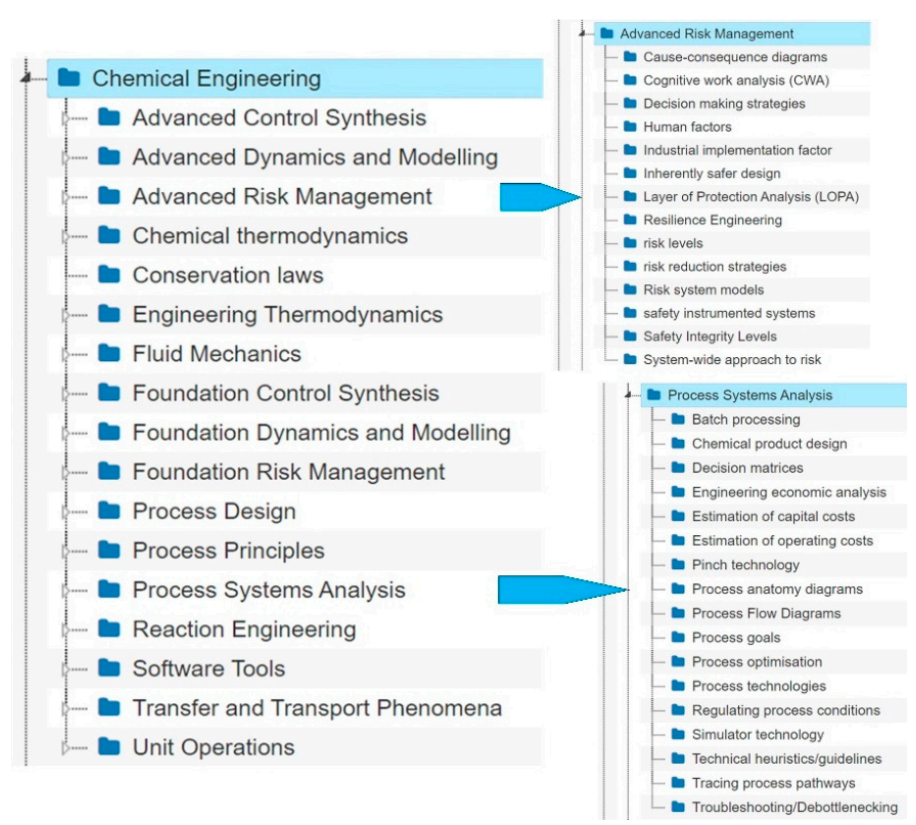

Figure 5. Knowledge taxonomies for Chemical Engineering (domain/sub-domain/topic). 


\subsubsection{Learning Unit Design}

The key object in any curriculum design is the learning unit. This requires the integration of many elements in Figure 3:

1. The intended learning outcomes (ILOs);

2. The required prior learning (RPL);

3. The assessment of ILOs: what, when, how and weightings;

4. The attainment objects within the unit;

5. The learning activities;

6. The knowledge domain, sub-domain and specific topics;

7. The complexity of the topics and tasks;

8. The learning spaces or places to be utilized;

9. The chosen andragogies.

This object is complex and could be regarded as analogous to a process engineering unit of a flowsheet. Learning outcomes can be built by using a defined but flexible syntax that uses the various taxonomies displayed in Figure 3. Structuring the ILOs provides significant power to reason over the completed curriculum and also visualize the characteristics of the curriculum. An example ILO from an advanced modeling course introducing the theory and practice of hybrid modeling is shown in Figure 6.
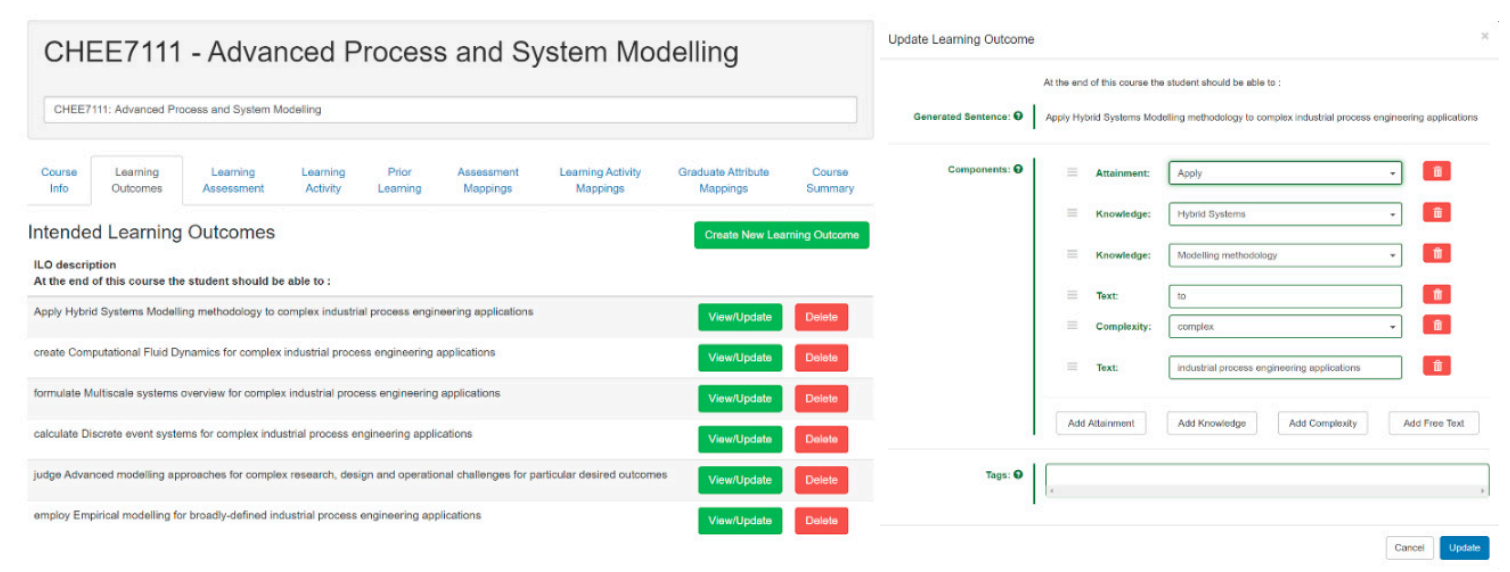

Figure 6. Example of intended learning outcomes (ILOs) (left) and the structured text ILO builder (right).

Moreover, the various tabs on the course profile show the other course-building options that are used in fully specifying the course characteristics. They include assessment items, learning activities, prior learning for the course and important mappings to professional competences.

\subsection{Pathways}

Curriculum designs ultimately lay down a series of learning pathways, professional attributes and competency development. As noted previously in the introduction, the program schema elements are developed incrementally across the length of the program. The representation and tracking of this incremental development are a crucial part of the design process.

For example, we often desire to understand the linkages within years and across years. This is similar to process streams passing through operating units. A simple visual illustration of course integration via learning outcomes is shown in Figure 7 [17]. 


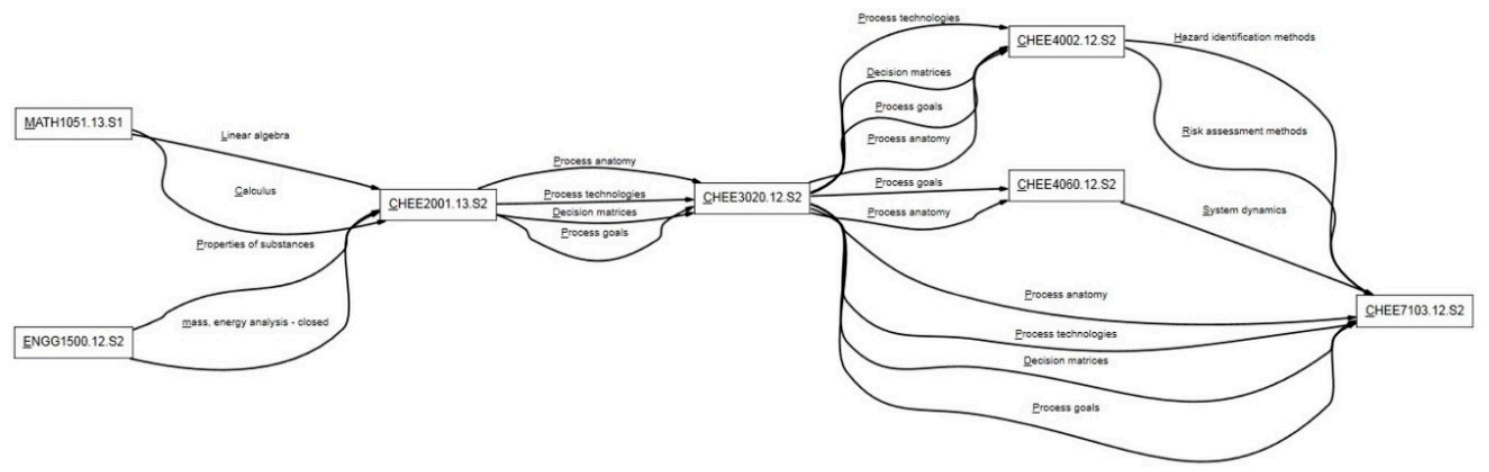

Figure 7. Example of knowledge domain outcome linkages for process system courses. (By permission of Engineers Australia [17]).

\section{Curriculum Design: The Journey Maker Computer-Aided Design Environment}

In the previous sections, we described the importance and challenges of complex curriculum design. The key goals were discussed, as well as the design information and processes required to build curricula. The development of a comprehensive web-based design tool which is adaptable, extensible and editable provides for design across all disciplines across higher education. Importantly, it was also developed for student use in building personalized curricula and visualizing the impact of choices. This is particularly important in the Arts and Humanities disciplines.

The functionality of this curriculum environment includes the following [17]:

- The ability to describe knowledge and skill domains and their interlinking across space and time;

- The ability to describe and track intended learning outcomes (ILOs) and attainment levels across space and time;

- The ability to describe the context and complexity of the planned learning;

- The ability to describe the spaces and places where learning is planned to happen;

- Linking assessment activities to ILOs and learning activities for promoting learning and proving outcomes;

- Ease of use by program coordinators and academic staff;

- Use by students to gain insight into the characteristics of a designed curriculum, and potentially to design and track the "experienced" curriculum;

- The ability to interface to other systems, such as institutional course and subject profiles;

- The ability to embed within the environment current "best practice" concepts and design processes as a vehicle for innovative curricula and better-informed academic use;

- The ability to adapt the environment across disciplines.

The majority of this functionality was developed in 2011/2012 as a standalone application [17]. The further development expanded activity across all university faculties, resulting in a web-based environment called The Journey Maker. The environment has two major components: a design component and a visualization component called "The Visual Journey". Figure 8 shows the entry page to the development environment, showing the design functions available for use in building and visualizing curricula. 


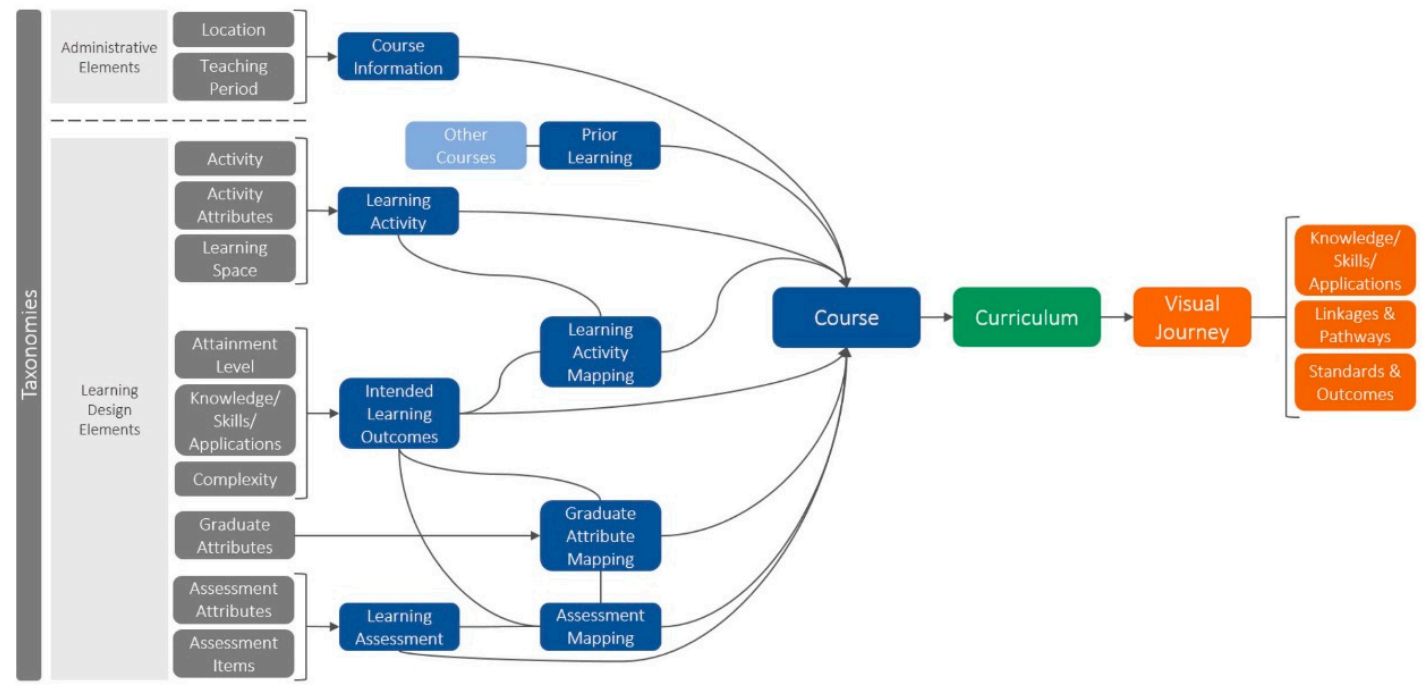

Figure 8. Overview of The Journey Maker design-environment functionality.

Elements of this environment are illustrated in the next section, using the design of some selected learning units, as well as showing an overall five-year curriculum design.

\section{Case Study in Curriculum Design: A Five-Year Chemical Engineering Program}

As a case study to display the development of a curriculum, we use the design of a five-year combined Bachelor and Masters Chemical Engineering program (BE/ME) at The University of Queensland. This is sufficiently complex, to demonstrate the design tools and the visualization tools that give deep insight into the design. The overall program structure is shown in Figure 9. This program typically has four learning units per semester, including elective options, which are shown as "+" options in each semester. These are chosen by students to fulfill their degree requirements, build specializations and address personal interests. There are 10 semesters in this program, with industry placements in Year 4, Semester 2.

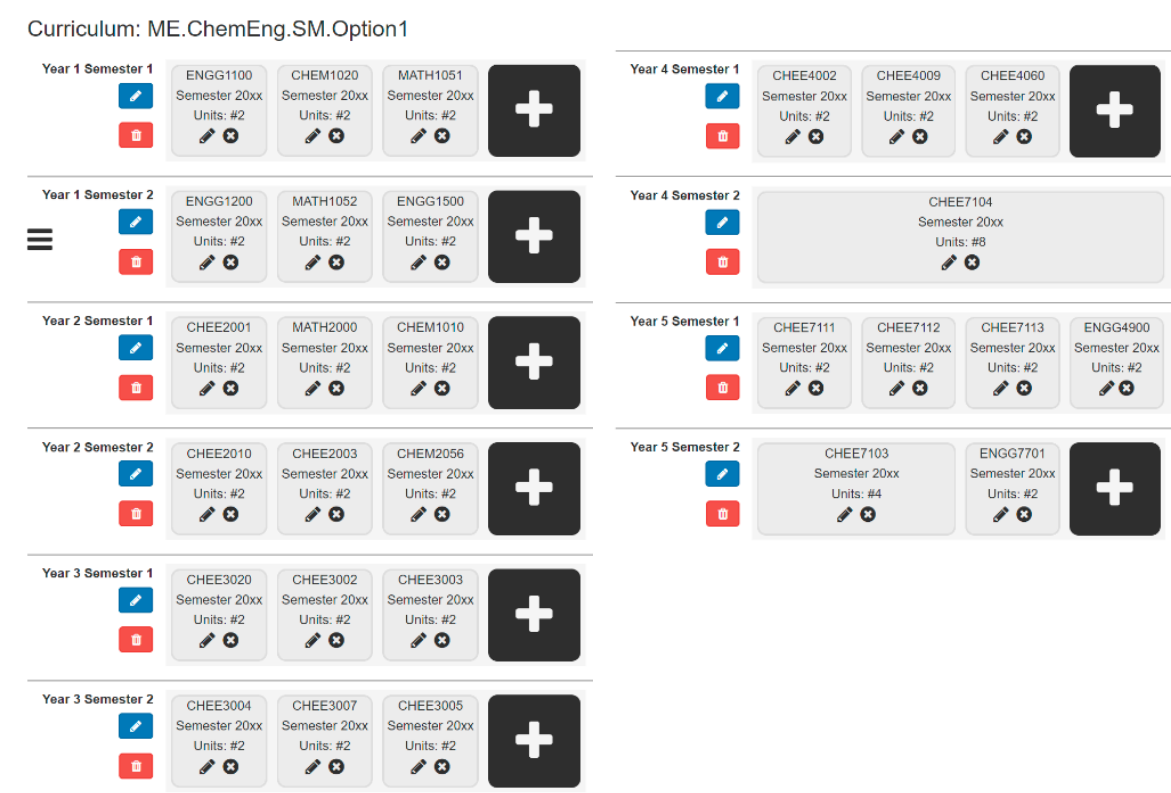

Figure 9. Compulsory course requirements for five-year BE/ME program. 
As shown in Section 3.2.2, all the course profiles have been built by using the course builder, and so they have a rich description of the learning within each module and also the connectivity throughout the curriculum. It is possible to investigate this particular design through the use of the visualization facilities within "The Visual Journey" web environment.

\section{Overall Curriculum Characteristics}

The visualization is able to view the overall picture of the curriculum as seen through the ILOs. Figure 10 shows the relative frequency of ILOs across the principal domains of the program. Clearly, the knowledge domain of Chemical Engineering dominates, but we also see the relative emphases around professional competences and the basic sciences: mathematics and chemistry. These insights might lead to unit-level or curriculum-level redesigns, depending on overall outcomes requirements. The visualizations can be presented in many ways: frequency, weighted frequencies and the like.

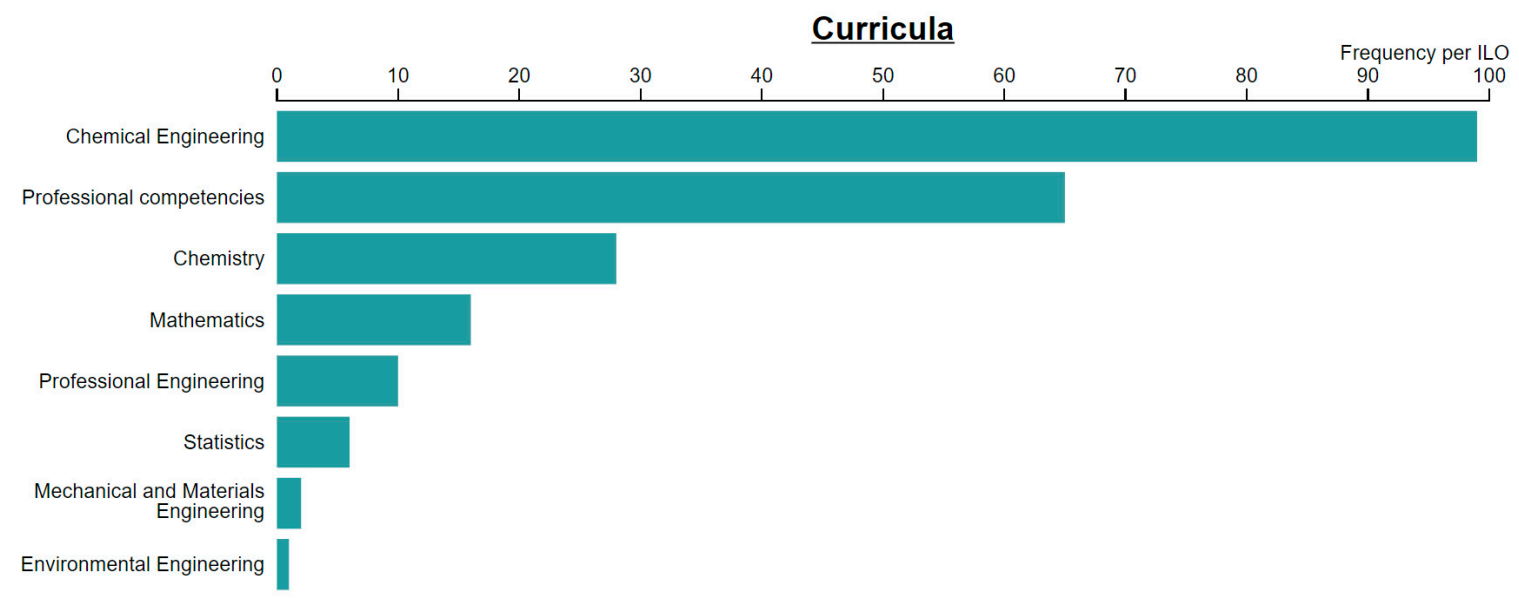

Figure 10. ILO frequencies for major knowledge domains across whole curriculum.

For further insights, the individual domains can be expanded, as seen in Figure 11, which focuses on the sub-domains within the Chemical Engineering domain. The thumbnail of the whole curriculum can be viewed to see where a specific focus might occur. In this case, process design can be seen within the ILOs across a series of courses starting in Year 1.

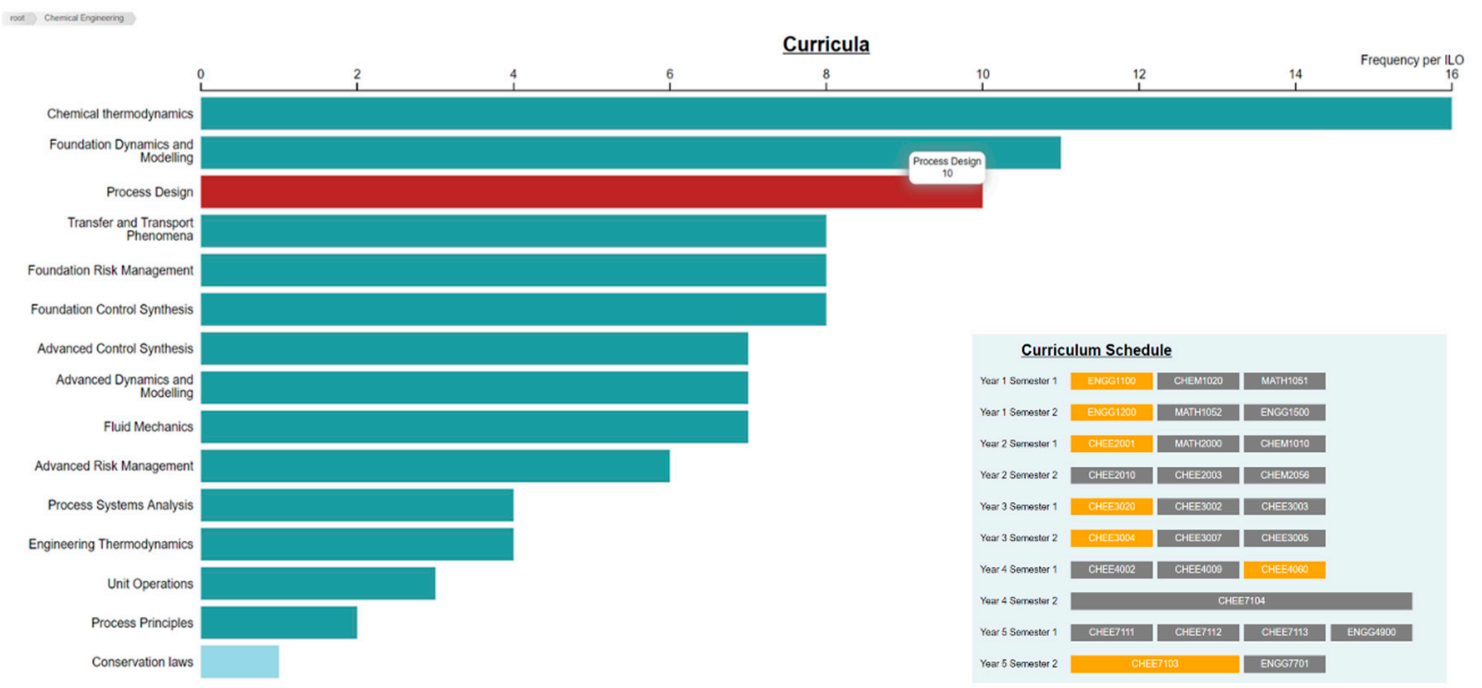

Figure 11. Lower-level domain knowledge visualization and location within the curriculum. 
This form of visualization, and many others, can also be applied to other aspects of the learning outcomes, such as cognitive objectives as described by Bloom's taxonomy. Figure 12 shows the distribution of ILOs where "synthesis" is a major objective within courses. In particular, the issue of synthesis described by "design" can be seen in later years of the curriculum. If some redistribution of that attainment to earlier years was considered important, then the visualization helps in redesign.

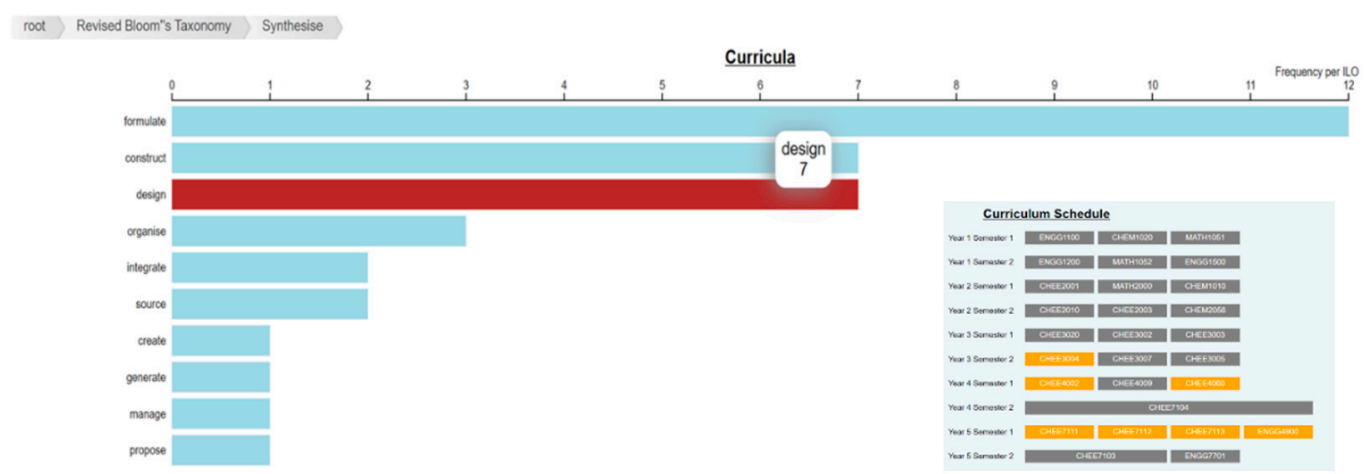

Figure 12. Attainment levels and distribution across the curriculum.

As well as considering issues around where knowledge, use of knowledge and personal attributes are developed, it is important to understand the linkages through the curriculum. This is particularly important as curriculum evolves, and in many cases, fragmentation occurs over time due to loss of integration. Figure 13 shows the connections of a particular ILO into following courses. Loss of that ILO due to changes in the learning unit could be important. The alluvial plots also allow unit instructors to see the position of the unit in relation to other units from a learning perspective. They see the required prior learning and also the future use of learning outcomes.

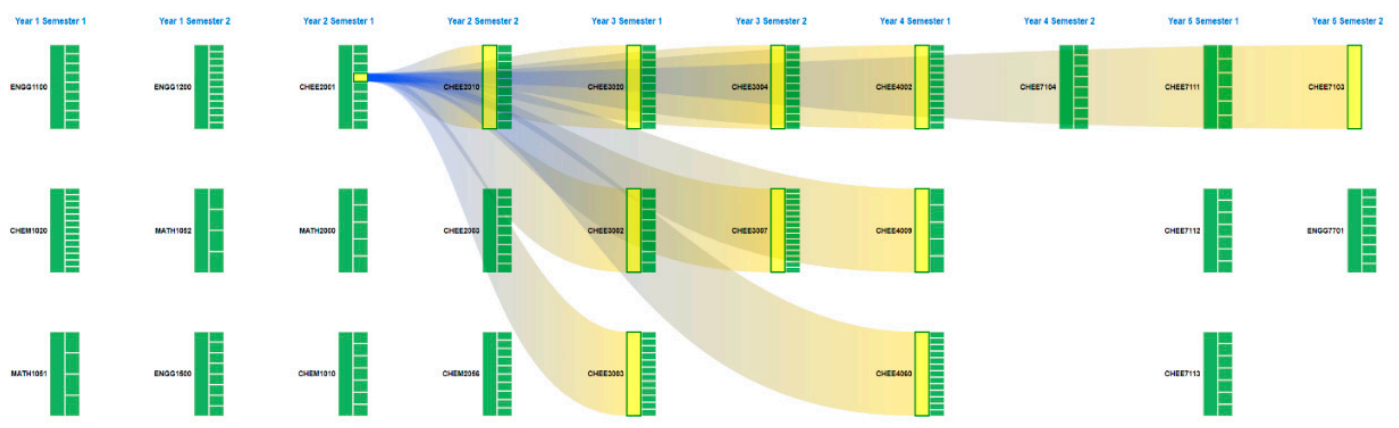

Figure 13. Tracking the linkages of a specific learning outcome through courses in the curriculum.

Figure 14 shows how course integration occurs across the curriculum. It shows key linkages along important learning pathways and identifies what might be "orphaned" courses within the curriculum.

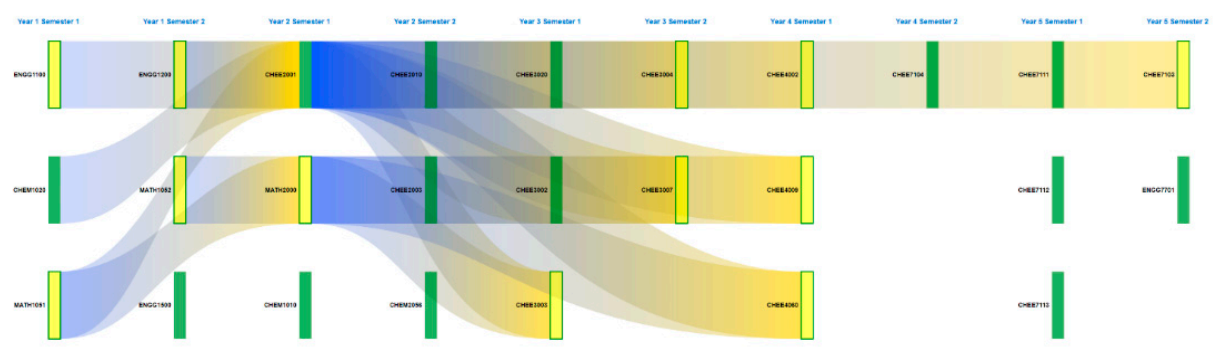

Figure 14. Tracking linkages between courses that have specified required prior learning.

Many other tabular and graphical views can be generated due to the structured descriptions and taxonomies embedded within the design environment. Within the approach, there is a very extensive 
subsystem for designing the assessment strategies. Figure 3 shows the extent of all the curriculum components, which cannot all be discussed in this paper.

These provide the ability for any discipline to develop curricula that is sharable, easily updated and extensible for the specific issues often dealt with in higher education programs.

The effects of using these formalized approaches, as described in these developments, are that now staff and students can clearly see the interconnections within curricula and are able to see the flow of knowledge and skills that are needed for future learning. It also allows curriculum changes to be easily mapped and tracked over time, providing easy access to professional accreditation organizations to see the impact of those changes. The ability to visualize learning outcomes and the forms of assessment used to provide evidence of attainment levels is an important aspect of the design.

Due the structured, extensible nature of all the curriculum building blocks outlined in Figure 3, it is relatively easy to export a wide range of reports, visualizations, curriculum data and statistics for numerous purposes.

\section{Conclusions}

This work has shown the use of certain PSE principles in developing complex curricula. The design of curricula resembles in many ways the basic ideas of process design and flow sheet development, since curricula design is an educational process. Through the understanding of the crucial building blocks for curricula and the structured manner of developing learning units, it is possible to produce whole curricula designs that capture the many characteristics that make up complex learning environments.

By using structured information management approaches, the final designs can be visualized to understand the whole integrated curriculum. The fundamental concepts, organization and deployment started within Chemical Engineering, but they have now been adopted and used in many other disciplines, including nursing, science, agriculture, pharmacy, veterinary science, medicine and philosophy. It is significant that the idea of the importance of an integrative approach rather than disparate designs was at the heart of the PSE efforts of Roger Sargent from the very beginning of his long and distinguished career.

The application of PSE ideas to bring an integrative approach to curriculum design now yields similar benefits to many other disciplines that have already been realized within the PSE community.

Author Contributions: Conceptualization, I.C. and G.B.; methodology, I.C. and G.B.; software, eLIPSE.; formal analysis, I.C. and G.B.; investigation, I.C. and G.B.; resources, I.C. and G.B.; data curation, I.C.; writing-Original draft preparation, I.C., G.B.; writing-Review and editing, I.C. and G.B.; project administration, I.C. and G.B.; funding acquisition, I.C. and G.B. All authors have read and agreed to the published version of the manuscript.

Funding: We acknowledge funding from The University of Queensland, Technology Enabled Learning (TEL) Grant scheme.

Acknowledgments: We acknowledge the web development work of the Centre for eLearning Innovations and Partnerships in Science and Engineering (eLIPSE). We thank Erzsébet Németh (E.N.) for her work on the visualization aspects of curricula.

Conflicts of Interest: The authors declare no conflict of interest. The funders had no role in the design of the study; in the collection, analyses or interpretation of data; in the writing of the manuscript; or in the decision to publish the results.

\section{References}

1. Sargent, R.W.H. Integrated Design and Optimization of Processes. Chem. Eng. Prog. 1967, 63, 71-78.

2. Williams, T.J. Systems Engineering for the Process. Industries; McGraw-Hill: New York, NY, USA, 1961.

3. Sargent, R.W.H. Chemical Engineering and Engineering Science. Chem. Eng. 1963, 168, 151-155.

4. Dewey, J. Democracy and Education: An introduction to the Philosophy of Education; The MacMillan Company: New York, NY, USA, 1916.

5. Tyler, R.W. Basic Principles of Curriculum and Instruction; University of Chicago Press: Chicago, IL, USA, 1949.

6. Barnett, R.; Coate, K. Engaging the Curriculum in Higher Education; Open University Press: Milton Keynes, UK, 2005. 
7. Hicks, O. Curriculum in Higher Education-Hello? in Enhancing Higher Education, Theory and Scholarship. In Proceedings of the 30th HERDSA Annual Conference [CD-ROM], Adelaide, Australia, 8-11 July 2007.

8. Ambrose, S.; Bridges, M.W.; Lovett, M.C.; DiPietro, M.; Norman, M.K. How Learning Works: Seven Research-Based Principles for Smart Teaching; Jossey-Bass Publishers, John Wiley \& Sons: San Francisco, CA, USA, 2010.

9. National Research Council. How People Learn: Brain, Mind, Experience and School, Expanded Edition; National Academy Press: Washington, DC, USA, 2000. [CrossRef]

10. International Engineering Alliance (IEA). Available online: https://www.ieagreements.org/ (accessed on 14 October 2019).

11. ABET, Accreditation Board of Education \& Technology. Available online: http://www.abet.org/accreditation (accessed on 14 October 2019).

12. European Network for Accreditation of Engineering Education (ENAEE). Available online: https://www. enaee.eu (accessed on 14 October 2019).

13. Oliver, B.; Ferns, S.; Whelan, B.; Lilly, L. Mapping the Curriculum for Quality Enhancement: Refining a Tool and Processes for the Purpose of Curriculum Renewal. In Proceedings of the Australian Quality Forum 2010, Gold Coast, Australia, 30 June-2 July 2010; pp. 80-88.

14. Roy, G.; Armarego, J. CCmapper: A Tool for Curriculum and Competency Mapping; Edith Cowan University, School of Engineering: Perth, WA, Australia, 2012.

15. JISC. The Design Studio. Available online: http://jiscdesignstudio.pbworks.com/w/page/12458422/Welcometo-the-Design-Studio (accessed on 14 October 2019).

16. SOFIA Interactive Curriculum Mapping. Available online: https://www.sofiacurriculum.com/ (accessed on 14 October 2019).

17. Cameron, I.; Birkett, G. A Curriculum Design, Modelling and Visualization Environment. In Proceedings of the 2012 AAEE Conference, Melbourne, Australia, 3-5 December 2012; Session 2B: Curriculum Design II, paper 1.

18. Requirements Engineering. Available online: https://en.wikipedia.org/wiki/Requirements_engineering (accessed on 14 October 2019).

19. Engineers Australia. Available online: https://www.engineersaustralia.org.au/About-Us/Accreditation (accessed on 14 October 2019).

20. UK Engineering Council. Available online: https://www.engc.org.uk/education-skills/accreditation-ofhigher-education-programmes/information-for-higher-education-providers/ (accessed on 14 October 2019).

21. EUR-ACE Framework Standards and Guidelines. Available online: https://www.enaee.eu/eur-ace-system/ standards-and-guidelines/\#standards-and-guidelines-for-accreditation-of-engineering-programmes (accessed on 14 October 2019).

(C) 2020 by the authors. Licensee MDPI, Basel, Switzerland. This article is an open access article distributed under the terms and conditions of the Creative Commons Attribution (CC BY) license (http://creativecommons.org/licenses/by/4.0/). 